Dicenda. Estudios de lengua y literatura españolas

ISSN-e: 1988-2556

http://dx.doi.org/10.5209/DICE.62150

\title{
El reflejo de Alejandro Sawa en los personajes bohemios barojianos
}

\author{
Rocío Santiago Nogales ${ }^{1}$
}

Recibido: 29 de marzo de 2016 / Aceptado: 28 de marzo de 2017

Resumen. Mucho anteriores a Rafael Villasús o al famoso Max Estrella valleinclanesco son otros personajes bohemios que Pío Baroja creó para sus novelas como contraposición a sus protagonistas. El escritor vasco no simpatizaba con un tipo de vida que se ejemplificaba en Alejandro Sawa, de tal modo que los estudiosos han querido ver tras esos personajes al propio escritor sevillano, pero sin profundizar en un exhaustivo análisis comparativo entre realidad y ficción. Este estudio pretende justificar tanto las posibles asociaciones como dar motivos para rechazar otras.

Palabras clave: Alejandro Sawa; Pío Baroja; personajes; bohemia.

\section{[en] Alejandro Sawa in Pio Baroja's bohemian characters}

\begin{abstract}
There are some bohemian characters that arrived later than Rafael Villasus or Max Estrella. They were made as opposed to the principal character because Pio Baroja did not like bohemian life and, precisely, Alejandro Sawa was the most significant bohemian writer, so many researches have wanted to see Sawa behind those characters. The problem is that there is not a deep analysis about them. This research is a comparison between fiction and reality so, at the end, we will know if these bohemians could be Sawa.
\end{abstract}

Keywords: Alejandro Sawa; Pio Baroja; characters; bohemia.

Sumario: 1. Introducción; 2. Los bohemios barojianos; 2.1. Juan Pérez del Corral y Betta; 2.2. El francés Caruty y el ruso Ofkin; 2.3. Fermín García Pipot y César Andion; 3. Conclusiones.

Cómo citar: Santiago Nogales, R. (2018). El reflejo de Alejandro Sawa en los personajes bohemios barojianos, en Dicenda. Estudios de Lengua y Literatura Españolas, 36, 307-324.

\section{Introducción}

Casi por definición, sean cuales sean los acontecimientos que se narran en una novela en la que los personajes se han inspirado en personas reales, van a estar distorsionados. ¿Qué grado de verdad tenemos derecho a presuponer cuando se dice que un personaje es Alejandro Sawa (1862-1909)? Es más, ¿el simple hecho de apreciar ciertas similitudes con la realidad basta para decir que un personaje se basa en determinada persona?

\footnotetext{
$1 \quad$ PDI en formación de la UNED

rsantiago@flog.uned.es
} 
No hay lugar a duda de que el personaje más famoso inspirado en el rey de los bohemios por antonomasia es Max Estrella. Sin embargo, antes de llegar a él, hay que recorrer otro camino que lleva a obras anteriores a Luces de Bohemia ${ }^{2}$ (1924) y, curiosamente, son de Pío Baroja (1872-1956): Aventuras, inventos y mixtificaciones de Silvestre Paradox (1901), Aurora roja (1904), Los últimos románticos (1906) y El árbol de la ciencia (1911). Decimos "curiosamente" porque las relaciones entre Alejandro Sawa y Pío Baroja se debatieron siempre entre el odio y el reconocimiento mutuos, algo que queda reflejado no solo en la ficción, dado que las palabras que el vasco puso en boca de sus personajes para aludir a Sawa no son las únicas referencias que tuvo hacia él. Ahora bien, es extraño que no se les haya prestado demasiada atención a las tres primeras obras barojianas que mencionamos. El personaje de Rafael Villasús de El árbol de la ciencia (1911) ha sido estudiado en comparación con Max Estrella, con quien tiene muchas similitudes, aunque también sustanciosas diferencias; pero existen más obras en las que Alejandro Sawa se deja entrever, acentuando muchísimo los signos que configuraban su personalidad, vista desde el prisma de Baroja, a quien no le agradaba en absoluto la vida bohemia. Se trata de personajes que tienen intervenciones más extensas que Villasús y, lo más interesante, fueron creados en vida de Sawa. El simple hecho de que Baroja recurra tanto al sevillano y a su entorno para crear a los bohemios de sus novelas le da a Sawa plena vigencia en su tiempo como modelo; en este caso es ejemplo contrario a lo que Baroja quería predicar, pero eso conlleva el efecto colateral de concederle relevancia aunque sea por contraposición. Por supuesto, esta circunstancia es para la investigación un arma de doble filo. Por un lado, sirve para dar cuenta de la fama que Sawa tenía en vida, pese al destierro literario que sufrió tras una muerte rodeada por la ceguera, la pobreza y la soledad. Asimismo, abre la puerta a analizar a otros personajes que nunca se han tenido en cuenta más que de un modo superficial. Por otro lado, es un impedimento porque, incluso antes de morir, en Alejandro Sawa ya se mezclaban la literatura y la realidad.

Este estudio tiene por objetivo estudiar a todos los personajes barojianos que en algún momento la crítica ha identificado con Alejandro Sawa, exceptuando a Rafael Villasús, compararlos con datos reales y elaborar las pertinentes justificaciones que nos permitirán aceptar o no la identificación.

\section{Los bohemios barojianos}

\subsection{Juan Pérez del Corral y Betta}

Para seguir el orden cronológico, debemos comenzar por la historia de Silvestre Paradox, protagonista de la trilogía La vida fantástica, compuesta por Aventuras, inventos y mixtificaciones de Silvestre Paradox (1901), Camino de perfección (pasión mística) (1901) y Paradox rey (1906). Parece que subyace en este protagonista una especie de autobiografía bastante adornada de su propio autor ${ }^{3}$. Paradox se encuentra

2 Antes de la edición definitiva de 1924, Valle-Inclán fue publicando Luces de Bohemia por fragmentos durante varias semanas, del 31 de julio al 23 de octubre de 1920, en la revista España.

3 Tras los protagonistas de las novelas de Pío Baroja se suele esconder el propio escritor de un modo autoficcional. 
con otro personaje, a quien Baroja llama Juan Pérez del Corral, que mucho tiene que ver con Sawa. Dice Allen Phillips:

En las memorias y otros libros autobiográficos de Baroja hay una inmensa galería de personajes pintorescos con quienes topaba en su larga vida de vagabundeo. De ahí las frecuentes semblanzas, a menudo caricaturas, de figuras reales de la bohemia madrileña. En sus novelas [...] la bohemia literaria y anarquista desempeña un papel considerable, y el autor, al fundir en la ficción rasgos típicos de todo bohemio, solía aportar a la realidad vivida datos imaginarios [...] El retrato de Juan Pérez del Corral que figura en Aventuras, inventos y mixtificaciones de Silvestre Paradox (Capítulo XI) parece basarse al menos en parte en algunos atributos nada halagüeños de Sawa, de nuevo trasplantado a Madrid después de haber residido en París. Arengaba a los reyes de piedra en la Plaza de Oriente; declamaba trozos teatrales; y a ese señor petulante y soberbio se le aplicaba el adjetivo divino (Phillips, 1985: 346-347).

Algunos de los fragmentos más significativos de las intervenciones y descripciones de tal personaje son las que siguen a continuación. Los hemos seleccionados por ser los más identificables con la vida de Sawa, criticada bajo los principios barojianos y por oposición a Paradox:

Salieron los tres a la calle, y como Pérez del Corral se marchaba, Amancio empezó a hablar mal de él, diciendo que era lo más insolente, vanidoso y majadero que podía ser un hombre [...] (Baroja, 1998: 147). Pérez del Corral mentía con una tranquilidad admirable, [...] Tenía una memoria admirable, una petulancia de damisela, una soberbia satánica y, a veces, rasgos de un desprendimiento y de una generosidad de gran señor. [...] Algunas noches, cuando salía del café la tribu harapienta, Pérez del Corral arrastraba a las masas a la plaza de Oriente, y allí arengaba a los reyes de piedra, o, acercándose a un árbol, para dar pruebas de sus facultades de actor, gritaba, no se podía decir que declamaba, un parlamento de Don Juan Tenorio o de Los amantes de Teruel (Baroja, 1998: 160).

De Sawa se dijo que conocía de memoria sus propios artículos, así como los versos de Paul Verlaine (1844-1896) y toda una serie de anécdotas que declamaba en las tertulias con gestos exagerados y gran solemnidad dramática. Debía ser todo un espectáculo, si bien muchos, entre ellos Baroja, lo tildaban de soberbio, déspota y arrogante. Su dualidad podía observarse también a la hora de convidar. En ocasiones generoso y en otras dejando descuidadamente y por pura necesidad que pagasen otros, lo que le confirió fama de aprovechado o de "gorrón" según el argot coloquial.

Por otro lado, Ernesto Bark (1858-1922) habla, en su Santa Bohemia (1913), de un proyecto que Sawa tenía en mente: fundar El Cenáculo, la asociación que distinguiría a la bohemia intelectual de la vulgarmente llamada "golfemia". Quizás, el siguiente pasaje tenga algo de relación con aquella idea:

— ¡Ah, señor Paradox, el encontrarnos ha sido providencial! Precisamente estos señores -y señaló a los que le acompañaban- van a fundar una revista, una cosa monstruosa... inaudita... ochenta mil suscripciones seguras, todos los Casinos, Ateneos, Academias, Corporaciones científicas, subvención de 
-Bueno -interrumpió Silvestre- ¿Y qué pito voy a tocar yo en esta revista? (Baroja, 1998: 142).

Tomando citas literales, la idea de El Cenáculo era descrita por Ernesto Bark del siguiente modo:

Es la fraternidad entre todos los pueblos que practicará esta Hermandad de peregrinos de la Verdad y Justicia, bautizada por su gran rabino en su biblia bohemia, que serán las "Iluminaciones en la Sombra" [...]

Ahí va la invitación al "Cenáculo": los poetas y poetisas de la vida:

Habíamos elaborado con Alejandro Sawa un reglamento, según el cual debían organizarse los ágapes mensuales de la abundante y variada tribu bohemia, tribu sugestivísima, puesto que encierra todo lo soñador e idealista de las letras, del arte, del periodismo y del intelectualismo en general.

- Serán socios solo los que ya tienen un nombre - dijo Sawa, con su exclusivismo de patricio de las letras-. Los pintores, actores y periodistas deben pasar por la criba de una Comisión purificadora para que la "Bohemia" no se confunda con la "Golfemia" (Bark, 1913: 5 y ss).

Ese mismo fragmento en el que Paradox no tiene ningún interés en colaborar con Pérez del Corral entronca con una propuesta que Sawa hizo realmente a Baroja para trabajar juntos y publicar un libro de experiencias parisinas. En sus Memorias, concretamente en la primera parte, Juventud y egolatría (1917), Baroja dedica unos párrafos al trato personal que tuvo con Sawa, poniendo de manifiesto que, pese a que ambos habían disfrutado de la vida parisina, poco tenían que ver el uno con el otro:

Un día Alejandro me escribió para que fuera a su casa. Vivía en la cuesta de Santo Domingo. Fui allí y me hizo una proposición un poco absurda. Me dio cinco o seis artículos suyos ya publicados y unas notas, y me dijo que añadiendo yo otras cosas podíamos hacer un libro de "Impresiones de París", que firmaríamos los dos. Leí los artículos y no me gustaron. Cuando fui a devolvérselos me preguntó:

- ¿Qué ha hecho usted?

- Nada. Creo que va a ser difícil que colaboremos los dos. No hay soldadura posible entre lo que escribimos.

— ¿Por qué?

- Porque usted es un escritor elocuente y yo no.

La frase le pareció muy mal (Baroja, 1917: 263 y ss).

Siguiendo con las peripecias de Pérez del Corral debemos destacar otro episodio:

Pérez del Corral, con un gesto de arrogancia, metió la mano en el bolsillo del pecho de su americana, y sacó un montón de papeles, que podían constituir un tomo. — ¿Qué es eso? -le preguntó Silvestre.

—Papeletas de casas de préstamos; ya veis si me quedará algo que empeñar.

Silvestre no tenía más que tres duros disponibles; pero esto no era óbice, como dijo Pérez del Corral, y fue bastante amable para guardarse aquel dinero. Luego añadió que si quería entregarle alguna alhaja o ropa, la tomaría también. Silvestre entregó al bohemio unos pantalones, una Historia de España, de Lafuente, y 
unas revistas inglesas. Pérez del Corral e Higinio fueron a empeñar todo esto y encontraron quien les diera dinero. El producto del empeño lo jugaron y ganaron (Baroja, 1998: 197).

A Alejandro Sawa lo ahogaban las deudas económicas hasta tal punto que murió en la más absoluta miseria. Para obtener dinero empeñaba todo lo que podía en el Monte de Piedad (Correa Ramón, 2008: 242-243) y rogaba a sus amigos, con gritos de desesperación en forma de misiva, que tuviesen a bien prestarle unas pesetas. El caso más notorio ocurrió con Rubén Darío (1867-1916), a quien hizo no pocas llamadas de auxilio y acabó, ante la negativa del nicaragüense, por reclamarle una deuda casi olvidada. Por el contrario, el poeta José del Castillo Soriano (1849-1928) sí se solidarizó con el bohemio dándole una pequeña ayuda (Correa Ramón, 2008: 234-235), al igual que hizo su íntimo amigo Enrique Cornuty (Correa Ramón, 2008: 251). A Baroja también le pidió dinero, no en calidad de amigo sino con prepotencia y capricho y sin intenciones siquiera de devolver el favor. Así lo relataba el escritor vasco:

A Alejandro Sawa le conocí una noche en el café de Fornos, estando yo con un amigo.

La verdad es que no había leído nada suyo, pero me impuso su aspecto. Un día fui tras de él, dispuesto a hablarle, pero luego no me atreví. Unos meses después le encontré una tarde de verano en Recoletos, con el francés Cornuty. Cornuty y Sawa fueron hablando, recitando versos, y me llevaron a una taberna de la plaza de Herradores. Bebieron ellos unas copas, pagué yo, y Sawa me pidió tres pesetas. Yo no las tenía, y se lo dije.

— ¿Vive usted lejos? -me preguntó Alejandro, con su aire orgulloso.

- No; bastante cerca.

- Bueno, pues vaya usted a su casa y tráigame usted ese dinero.

Me lo indicó con tal convicción que yo fui a mi casa y se lo llevé. Él salió a la puerta de la taberna, tomó el dinero, y dijo:

- Puede usted marcharse.

Era la manera de tratar a los pequeños burgueses admiradores, en la escuela de Baudelaire y Verlaine (Baroja, 1917: 263 y ss).

De igual modo y a propósito de los juegos de azar, también se sabe que Alejandro se dejó seducir por los "tapetes verdes" (Correa Ramón, 2008: 202). Por supuesto, el asunto concreto de la novela barojiana no es una reproducción literal de ningún episodio de la vida de Alejandro Sawa pero Baroja, al condensar hábitos, anécdotas y características en una sola intervención, deja entrever los peores vicios que tenía y las penurias por las que pasaba Alejandro.

Asimismo, son abundantes los comentarios de reproche hacia los mundos que Baroja rechazaba. En la misma novela que estamos tratando, se puede leer la siguiente opinión: "Como parece, según los descubrimientos modernos, que hay una Providencia protectora especial de los golfos y de los abandonados, lo que no impide que de vez en cuando los deje morirse de hambre para que aprendan" (Baroja, 1998: 215).

Se trata de una sentencia muy dura. Ahora bien, es bastante probable que se dirija en términos generales. En sus Memorias, Baroja relata cómo se encontraba 
con Alejandro Sawa de vez en cuando y se paraban a charlar e intercambiaban algún cumplido, aunque no congeniasen. En general, Baroja no lo hacía con ningún miembro de aquel grupo literario-intelectual, ni aprobaba su estilo de vida. Pero en vez de la total indiferencia hacia ellos, optó por la crítica feroz, lamentándose porque no sufriesen más males aquellos que deberían penar por sus conductas. La frase "lo que no impide que de vez en cuando los deje morirse de hambre para que aprendan" es especialmente cruel. A pesar de tratarse de una ficción donde Paradox no es del todo Baroja y Corral no es del todo Sawa, sino solo esencias o modelos, se entiende que Baroja aprobaba la muerte de algún bohemio a modo de escarmiento.

Quizás, lo que más llama la atención es que faltaban aún ocho años para que Sawa falleciese, de manera que lo que va a seguir a continuación es fruto únicamente de la casualidad, por lo que lo consideramos más anecdótico que científico. Nos vamos a referir a dos momentos de la novela: cuando Pérez del Corral está desaparecido por un tiempo y, de repente, envía una carta a Paradox para que acuda en su auxilio y cuando el personaje bohemio muere a causa de la tuberculosis:

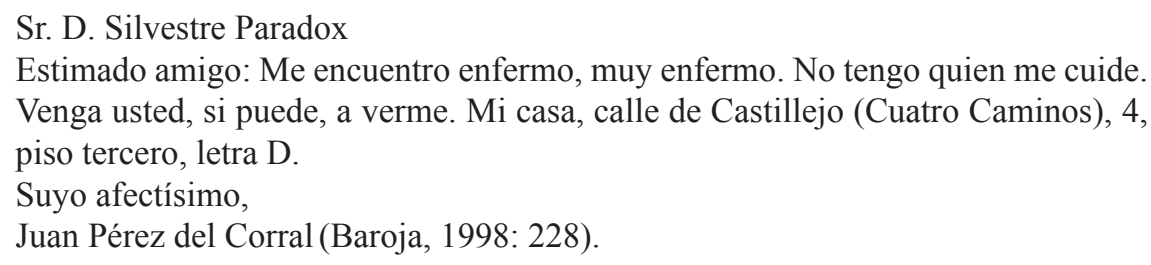

Como antes apuntábamos, Aventuras, inventos y mixtificaciones de Silvestre Paradox data de 1901, cuando Sawa aún no estaba ni ciego, ni enfermo, ni recluido en su casa. Las cartas de auxilio (ya fuese económico o espiritual) a sus amigos son de años posteriores. Sin embargo, son casi premonitorias esas palabras de "me encuentro enfermo" o "venga usted, si puede a verme". ¿Cuántas veces no suplicaría a Rubén Darío tal acción entre 1905 y $1908^{4}$ ?

Con respecto a la muerte de Pérez del Corral, Paradox aparece como el alma caritativa que se compadece de un "golfo, abandonado, bohemio y desarrapado". Se ocupa de que lo trasladen en camilla al hospital, le visita (de hecho, es la única visita que recibe) y cuando se produce el fatal desenlace de la muerte a causa de la tuberculosis, Paradox, solo y por cuenta propia, le da sepultura en el Cementerio Este. Es como si Baroja ofreciese una visión habitual y castigadora al tipo de vida que los de la condición de Pérez del Corral llevan. Además, opta por la tuberculosis, asociada casi por definición a la "golfemia".

Por otra parte, el segundo personaje que vamos a tratar de esta novela es Betta: "Otra de las figuraciones importantes del café era Betta, que se pasaba la vida alcoholizado, siempre impasible con su bello rostro árabe, de barba y pelo negrísimos, la pipa en la boca" (Baroja, 1998: 160). La descripción de Betta también encaja

4 La carta que Baroja hace escribir a Pérez del Corral pidiendo auxilio a Paradox se parecen demasiado a tres misivas reales que Sawa escribió a Darío en 1905: "Mi gran Rubén: estoy malo [...] Un gran saludo de admiración y un gran abrazo de amistad"; "[...] Ven en mi ayuda [...]” y “[...] Ven, ven en seguida. Te aguardo con impaciencia. Mis dos manos." Las cartas originales manuscritas se encuentran en el Archivo Rubén Darío, docs. 2008, 2009 y 2010. Reproducidas en Álvarez, 1963: 62-63. 
con la figura del bohemio, pues de Alejandro se decía que tenía cabeza de griego ${ }^{5}$, era moreno, con barba y fumaba en pipa. El profesor Gutiérrez Carbajo dice que: "Allen Phillips no encuentra mucho parecido entre Alejandro Sawa y Juan Pérez del Corral, descontados los rasgos genéricos de todo bohemio, y ve más semejanzas con Betta, otro de los personajes de esa misma novela" (Gutiérrez Carbajo, 1999: 26).

El problema es que en las páginas siguientes de la novela se dice de Betta que era más callado, cualidad no aplicable a quien declamaba a voces a altas horas de la madrugada y entraba ceremonioso en los cafés. Esto abre bastantes interrogantes sobre la identificación del personaje. Puede ser Rubén Darío, quien también era de tez oscura, tenía problemas con la bebida y frecuentaba las tertulias; o Valle-Inclán, pues Betta acompaña a Corral a exigir una satisfacción, lo que recuerda que el gallego era aficionado a batirse en duelo; incluso podría ser un desdoble de Sawa y de todos aquellos de quienes se rodeaba, posiblemente para dar a entender que en cuanto a la apariencia todos guardaban cierta similitud, tal y como comenta Gutiérrez Carbajo al hablar de "rasgos genéricos de todo bohemio". O quizás, solo sea un invento de Baroja que funciona a modo compañero de Pérez del Corral ${ }^{6}$. En cualquier caso, ante la imposibilidad de establecer un vínculo fiable, dejaremos apuntadas estas posibles correspondencias como hipótesis.

De haber sido personajes sin más, irreconocibles en una persona concreta, la novela hubiese sido simplemente eso, una narración contada desde el punto de vista de la moral de Baroja. Pero al ser identificables ciertos comportamientos precisos, cabe esperar una mala reacción por parte de Alejandro quien, claro está, pudo leer la novela. De hecho, en Juventud, egolatría (1917), el vasco menciona que Sawa se molestó por haber sido retratado en una novela: "Pasado algún tiempo, le dijeron a Alejandro que yo le había pintado en una novela y me tomó cierto odio. A pesar de esto, de cuando en cuando nos veíamos y hablábamos afectuosamente" (Baroja, 1917: 263 y ss).

No matiza en cuál y, aunque Pérez del Corral nos ha demostrado que perfectamente pudo ser él la causa del enfrentamiento, no hay que perder de vista que faltan otras dos novelas barojianas por analizar que se publicaron en vida del sevillano y por cuyas páginas desfilan adeptos a la bohemia.

\subsection{El francés Caruty y el ruso Ofkin}

Es en la tercera parte de su trilogía La lucha por la vida, formada por La busca (1904), Mala hierba (1904) y Aurora roja (1904), cuando Baroja hace el retrato de un personaje francés que también se ha identificado con Sawa. Así lo dice Iris Zavala: "Se dice que el francés de Aurora roja (1904), de Baroja, es Sawa" (Zavala, 1977: 35). Es un caballero al que Baroja llama Caruty, procedente de Francia que no habla correctamente el castellano, que da grandes apretones de manos, hace reverencias y viaja a modo de vagabundo. No es descabellado pensar en Alejandro Sawa puesto que hay ciertas coincidencias: el exceso de ceremonia, el alarde de su estancia en París y de su acento y las miserias que pasaba. Es más, Baroja re-

5 Griego y árabe se podrían aceptar como equivalentes por analogía dada la similitud de rasgos que se pretenden destacar: pelo negro, ojos oscuros y barba.

6 Se podría vislumbrar una especie de don Latino o de viejo borracho de melenas que llega al entierro de Villasús. 
cordaba que el bohemio sevillano también acostumbraba a dar grandes apretones de manos:

Después, cuando publiqué Vidas sombrías, algunas veces, a las altas horas de la noche, le solía ver a Sawa, con sus melenas y su perro. Me daba la mano con tal fuerza, que me hacía daño, y me decía en tono trágico:

— Sé orgulloso. Has escrito Vidas sombrías (Baroja, 1917: 263 y ss).

En cuanto a la personalidad o apariencia física del tal Caruty se aporta lo que sigue:

Casi todos los domingos había presentación de un compañero en la Aurora Roja. Los dos más curiosos, por lo exóticos, fueron un francés y un ruso.

El francés era un joven anguloso, torcido, raro, con los ojos bizcos, los pómulos salientes y una perilla de chivo.

Se presentó dando grandes apretones de mano y haciendo reverencias ceremoniosas a todos. Habló largamente de sus viajes de vagabundo. Él era el hombre de las carreteras; ninguno le entendía bien, parte porque hablaba incorrectamente el castellano y parte porque sus teorías eran incomprensibles (Baroja, 1904: 90).

Si tomásemos por bueno el juicio: "Se dice que el francés de Aurora roja (1904), de Baroja, es Sawa", pecaríamos al caer en generalidades no deseadas. Aunque ciertos rasgos relativos al comportamiento pueden encajar, físicamente Alejandro Sawa no era anguloso, ni bizco, ni estaba torcido. Su barba era tupida, no limitándose a una perilla y, quizás lo más llamativo, en 1904 era un señor de cuarenta y dos años y no un joven. Esto último nos hace despojar de contemporaneidad al texto respecto a su propio tiempo, cosa que podríamos aceptar dado que Baroja no se centra, como ya se ha visto en el epígrafe anterior, en episodios concretos, sino que condensa anécdotas y rasgos dando una visión global y a la vez tratada literariamente. De hecho, es habitual en las novelas de Baroja la manipulación del tiempo, comprimiendo en poco texto largos períodos o prolongando pequeñas anécdotas a lo largo de varias páginas.

El inconveniente, más allá de todo lo anterior, es que este personaje francés no encaja al superponerse con Sawa en cuanto a su aspecto, aunque parece que sí lo hace en sus intervenciones: "[...] yo he recitado los versos de papá Verlaine [...]" (Baroja, 1904: 122), "Caruty habló de sus paseos con el papá Verlaine, borracho por las calles de París [...]” (Baroja, 1904: 123). Referirse a Verlaine como "papá" nos hace evocar la admiración que tenía Sawa por quien consideraba su maestro, quien fue su amigo durante su estancia en París y la gran tristeza en la que se vio sumido tras la noticia del fallecimiento de su mentor. Sin embargo, Verlaine era todo un referente francés para los bohemios decadentes de principios de siglo, por lo que mencionarlo como padre no implica necesariamente la alusión a Sawa.

Existe otro pasaje protagonizado por Caruty, que es su intervención interrumpiendo un mitin:

Era Caruty que se había subido al asiento, pálido, con la mano abierta.

— ¡Fuera! ¡Fuera!, que se siente -gritaron todos, creyendo quizás que intentaba replicar al orador. 
—No, no me sentaré - dijo Caruty-. Tengo que hablar. Sí. Tengo que decir: ¡Viva la Anarquía! ¡Viva la Literatura! (Baroja, 1904: 136).

Si bien semejante reivindicación podía proceder perfectamente del autor sevillano, debemos prestar suma atención a los recuerdos de Pío Baroja:

Cornuty fue el que en un mitin anarquista del Teatro Barbieri gritó con entusiasmo: - ¡Viva la anarquía! ¡Viva la Literatura!

Esta equiparación de la anarquía con la literatura no se podía considerar disparatada, sino más bien certera, porque la anarquía de ese tiempo era cosa más literaria que política (Baroja, 1949: 837).

Sorprendentemente, existe una coincidencia literal. Es más, Zavala, pese a aportar la identificación del francés con Sawa, habla del tal Enrique Cornuty y se refiere tanto a Baroja como al episodio citado anteriormente: "[...] si preferimos el testimonio de Baroja, Enrique Cornuty, el francés que importó el decadentismo a España, fue de los primeros en equiparar anarquía y literatura, en un mitin celebrado en el teatro Barbieri" (Zavala, 1977: 30).

Enrique Cornuty era un amigo de Alejandro Sawa, un francés a quien había conocido durante su estancia en París. La doctora Correa especifica que: "El francés Enrique Cornuty (había) venido con toda probabilidad desde París poco después de que lo hiciera Sawa [...]" (Correa Ramón, 2008: 252), pese a que Baroja afirma que volvieron juntos: "Cornuty me dijo que llegó a Madrid con Alejandro Sawa: alquilaron entre los dos un cuarto [...]" (Baroja, 2006: 68). Sea como fuere, lo cierto es que eran amigos, habían convivido en París y ahora lo hacían en Madrid. Cornuty era de origen francés y presumiblemente no vocalizaría bien en castellano. Si a esto le sumamos la literalidad de las frases que pronuncia en la ficción y en la realidad y fonéticamente reparamos en el parecido entre Caruty y Cornuty, podemos afirmar que el francés de Aurora roja no pretende encarnar a Alejandro Sawa sino a su amigo Enrique Cornuty, con quien no vamos a negar que compartía ciertos aspectos de su personalidad, idolatraba igualmente a Verlaine ${ }^{7}$, y pertenecía a esa pandilla de bohemios a quienes Baroja considera desarrapados.

Para acabar de reforzar el discurso es necesario poner de manifiesto otras dos coincidencias asombrosas que no dejan lugar a la duda. En Aurora roja se da la siguiente conversación en la que la respuesta sale de los labios de Caruty:

- ¿Y no tienes familia, compañero? -le preguntó alguno.

- Sí - contestó él-, pero quisiera ver a mi padre, a mi madre y a mis hermanos, ahorcados en un jardín reducido (Baroja, 1904: 83-84).

Alonso Zamora Vicente recoge que los hermanos Baroja recordaban que Cornuty quería ver en la horca a su familia y que llamaba a Verlaine "papá":

Más pintoresco es el recuerdo de Enrique Cornuty, un francés que presumía de haber tenido en sus brazos a Verlaine en el momento de su muerte. (Yo, personalmente, creo que Verlaine se debió morir en los brazos de mucha gente de 
aquélla: era una condecoración inestimable el hablar de Papá Verlaine y enviarle muy cordialmente al otro mundo). Cornuty ha sido recordado por todos los del 98, probablemente por su natural disparatado y su poca consistencia. Murió anónimamente, en París, atropellado por un camión. Jamás logró emplear el verbo ser, que siempre se convertía en estar, ni supo utilizar pedir, que siempre salía en preguntar: "Amigo, usted que está un amigo devoto, ¿no podríamos entrar en uno de esos lugares de delicias, donde yo podría preguntar café?" A los Baroja les llamaba mucho la atención que Cornuty, hablando de su padre, dijera siempre esto: "El pequeño industrial que está mi padre no comprende mismo de la literatura. Yo le odio a él y a mis hermanos, y mi mayor placer estaría en verles ahorcados en un jardín reducido.” Lo del jardín reducido era una de las cosas que don Pío recuerda siempre de aquel tipo. Por lo visto, en esa dimensión espacial, la horca era más horca. La verdad es que el pobre Cornuty, autor de Haderías dolorosas, es otro de esos espectros desheredados y contradictorios que hacen bulto en las tertulias y divierten a los demás. Fue una de las principales víctimas de la gorronería de Alejandro Sawa, etcétera (Zamora Vicente: 1973: 43 y ss).

Además de la exactitud de las crudas palabras sobre el deseo que Cornuty tenía respecto al desenlace de su familia, lo cierto es que Alejandro Sawa nunca podría haber hecho semejante comentario dado que no solo apreciaba y tenía buen trato con sus hermanos, sino que una profunda desolación lo invadió cuando falleció su padre a quien cuidó, junto con su esposa, hasta el último momento.

Continuando con Enrique Cornuty, también los hermanos Baroja son los autores de las dos descripciones físicas más extendidas de él. Ricardo decía: "Era Cornuty flaquísimo. Cara de tártaro, ojos semibizcos [...]” (Baroja, 1969: 27); y Pío aportaba con más sarcasmo: "Cornuty parecía la inicial de una letra gótica: era flaco, juanetudo, con los ojos torcidos y una perilla de chivo" (Baroja, 1947: 94). Y del mismo modo que Sawa no coincidía en absoluto en la descripción de Caruty cuando nos referíamos a que Baroja lo pintó como un "joven francés anguloso, torcido, raro, con los ojos bizcos, los pómulos salientes y una perilla de chivo", Cornuty encaja a la perfección con estas palabras.

El otro personaje que aparece junto al francés en Aurora roja es un ruso:

Otro de los presentados fue un judío que se llamaba Ofkin. [...] Tenía el pelo castaño, la barba en punta, la mirada azul; era muy pálido; [...] Hablaba una mezcla de castellano, de italiano y de francés. [...] El auditorio del juego de bolos no se entusiasmó con el protylo tanto como el judío ruso (Baroja, 2006: 84).

Existen, al menos, tres datos que aportan sustanciosa información: la descripción, la cantidad de lenguas que habla y que lo llamaban "el judío ruso". Alejandro Sawa tenía un íntimo amigo llamado Ernesto Bark, que ya vimos que era el autor de $L a$ Santa Bohemia donde se explica el proyecto de El Cenáculo y se dice que Iluminaciones en la sombra iba a ser para ese grupo una especie de catecismo. Pues bien, Sawa en su obra describe así a Ernesto Bark:

Ernesto Bark, que lleva una llama por pelos en la cabeza, y cuyos ojos árticos lanzan miradas de fuego que ignoran las más ardientes pupilas meridionales [...] 
Nació en Riga o en Dorpart. [...] En el sintético lenguaje moderno podría llamársele un excesivo. ¿Tuvo, allá en sus mocedades, curiosidad del mundo? Recorrió Europa. ¿Tuvo el ansia intelectual de convertir la idea en dinamita? Fundó en Ginebra un periódico revolucionario. ¿Quiso diluirse en arte y armonía? Fue virtuoso en Italia (Sawa, 1977: 213).

Los ojos árticos se corresponden con la mirada azul, y Sawa nos informa de que su amigo residió en Italia, lo que también nos explica el dominio de la lengua italiana. También apunta el dato de su nacionalidad. Siendo que Estonia nos podría hacer rechazar la procedencia rusa, lo cierto es que había cierta confusión con respecto a sus orígenes exactos, pues se llegó a decir que era ruso, polaco o incluso alemán. La explicación nos la da Soriano-Mollá:

Solía denominarse livonés, "el letón revolucionario”, según Pío Baroja; cuando no, decía ser ruso, polaco, alemán... y español adoptivo. En realidad, la aureola de incertidumbre que creó en torno a su nacionalidad no es sino el resultado de sus afanes nacionalistas, patrióticos y, a la vez, cosmopolitas. Ernesto Mauricio Enrique Bark era hijo de Woldemar Heinrich Bark y Corinne Schultz, de origen estonio y alemán. Ernesto Bark nació en Kaava, dominio parroquial de Laiuse, cerca de Tartu (Dorpart), en la actual Estonia, el día 23 de Marzo de 1858. La multiplicidad de gentilicios que utilizaba se deben en parte a la conflictiva historia de Estonia y Letonia, países dominados constantemente por Polonia, Alemania y Rusia. Merced a ello, Bark se confiere en el prólogo de España y el extranjero las nacionalidades: "alemana etnográficamente, la rusa por política (y por desgracia) y la española por afirmación y amor..." (Thion Soriano-Mollá, 1998: 15).

Respecto a lo de judío, el puzzle va encajando cuando descubrimos la gran labor que hizo por este pueblo:

[...] cooperar con los revolucionarios rusos era una obligación moral [...] (Thion Soriano-Mollá, 1998: 21). El quehacer periodístico de Bark para estrechar las relaciones internacionales continuó en Madrid hacia 1887. Por aquel entonces, Isidoro López Lapuya, abogado muy activo en política, organizaba movimientos de emigración de judíos. Gran parte de ellos eran de origen ruso, López Lapuya desconocía la lengua y solicitó ayuda a Ernesto Bark como intérprete. A partir de entonces nació una gran amistad. Juntos proyectaron editar un libro en favor del pueblo judío y un periódico que se constituyese en portavoz de los judíos esparcidos por toda Europa (Thion Soriano-Mollá, 1998: 66). [...] junto con Isidoro López Lapuya encontraría un primer campo de acción ayudando a los judíos de origen ruso que llegaban a España [...] (Thion Soriano-Mollá, 1998: 304-305).

De este modo, la referencia de Baroja al personaje de Ofkin como "el judío ruso" estaría más que justificada. A pesar de que Sawa ya mencionaba que su amigo Bark residió en Italia, se nos confirma al decir: "Se le acusaba de sus actividades políticas en Suiza contra el poder ruso. Bark consiguió huir y se refugió durante algún tiempo en Italia" (Thion Soriano-Mollá, 1998: 23). Igualmente vivió en París, lo que justi- 
fica que hablase francés y desvela que, al igual que Cornuty, ya conocía a Sawa de aquel tiempo como residente en la capital francesa ${ }^{8}$ :

Puesto en libertad, Bark se dirigió como tantos otros refugiados políticos y bohemios a París. [...] Durante los meses que permaneció en París, Bark convivió con los bohemios y exiliados políticos españoles. Se reunía con Alejandro Sawa, Ricardo Fuente, Luis Bonafoux, Ruiz Zorrilla, Francisco Ferrer... (Thion SorianoMollá, 1998: 32).

Pese a que en este apartado hemos tenido que rechazar la identificación de Alejandro Sawa como personaje, es sumamente importante haber descubierto que la relación con él es más que evidente al corresponderse los dos caracteres con dos íntimos amigos suyos.

\subsection{Fermín García Pipot y César Andion ${ }^{9}$}

La última novela en la que nos hemos de detener es Los últimos románticos, la segunda parte de la trilogía El pasado, que engloba La feria de los discretos (1905), Los últimos románticos (1906) y Las tragedias grotescas (1907).

Dice Allen Phillips:

En Los últimos románticos, junto con otro tipo (Fermín García Pipot, que frecuentaba La Taberna Alsaciana con otros bohemios y revolucionarios de distinta factura) hay un poeta afrancesado (que recitaba en todo momento no a Verlaine como Sawa sino a Baudelaire) llamado César Andión pintado de una manera poco generosa, en cuyo carácter y modo de ser puede reconocerse más fácilmente a Sawa, modelo de tantos retratos (Phillips, 1985: 347).

Sin embargo, Zavala opta por asignar a Sawa otro personaje de esa misma novela de Baroja:

¡Qué extraño personaje este Sawa! Bohemio triste, recordado por don Pío y Manuel Machado como la primera persona que habló en España de Verlaine. "Era un pobre hombre sin ninguna penetración -escribe Baroja con falta de generosidad y poca perspicacia-, moreno, con cierto aire apostolar, melenas y barbas negras" (Memorias, VII: 136-137). Pero ya mucho antes se había interesado por él. Fermín García Pipot, el bohemio de Los últimos románticos (1906), es personificación de Sawa: flaco, capa española y un perro de lanas (Zavala, 1977: 36).

Esta contradicción se merece una pequeña reflexión. Tras leer los fragmentos que mejor informan sobre ambos personajes, podemos elaborar algún juicio contundente sobre cuáles son las coincidencias o incongruencias que hay para identificar o no a

8 No olvidemos que Pío Baroja viajaba con frecuencia a París y, pese a no relacionarse apenas con los bohemios allí residentes, es posible que supiese que allí vivían Alejandro Sawa, Enrique Cornuty y Ernesto Bark y que, además, eran buenos amigos entre ellos.

9 Pese a que en toda referencia aparece Andión, lo cierto es que el personaje se apellida Andion, sin tilde, como muestra la edición de Los últimos románticos de 1919 que aquí se cita. 
Sawa con ellos. En primer lugar, el protagonista de Los últimos románticos, Fausto, conoce a Fermín García Pipot:

[...] y el tartamudo de las botas de montar y de la capa española, llamado García Pipot, al cual había conocido don Fausto en el café Voltaire [...] (Baroja, 1919: 114).

- ¿Usted quiere vivir en un sitio pobre pero tranquilo? terminó diciendo Pipot.

- ¡Hombre, sí! ¡Ya lo creo! -Entonces, véngase usted a mi casa.

Don Fausto y Pipot se encaminaron hacia la calle de l'Arbalete; detrás del tartamudo iba su perro.

Pipot era un hombre de unos cuarenta y cinco a cincuenta años, flaco y raro. Tenía la mirada viva y penetrante, melenas encrespadas, el bigote ralo, la boca sumida y la nariz larga y arqueada. Vestía traje negro, desgastado y lustroso, y hablaba en su media lengua una mescolanza extraordinaria de castellano, catalán y argot de París.

Salieron don Fausto y Pipot a la calle, y una vez uno y otra otro, seguidos del perro, alternándose para llevar la maleta, llegaron a la calle de Ulm. Esperaron un rato, montaron en un coche y el perro subió con ellos.

Estaban en la calle Galande. Allí vivía Pipot. La casa era alta, negra, leprosa, con una porción de huecos, con las ventanas abiertas hacia afuera y los cristales rotos. [...] (Baroja, 1919: 132 y ss).

Yo, qué quiere usted -dijo Pipot-, tengo cierta debilidad por los perros, pero respeto su independencia. [...] (Baroja, 1919: 138).

Cada uno depositó su parte sobre la mesa y Pipot se entendió con la del mostrador para la comida; luego cogió los naipes y, retirándose hacia el mostrador, comenzó a hacer juegos de manos, sacando las cartas que primero mostraba entre sus dedos del interior de la americana, del pantalón y de la frente. La Abadesa y una muchacha del bazar estaban encantadas [...] (Baroja, 1919: 182).

Esperaron hasta que se presentó Nanette con la guitarra; Pipot la tomó y echó a andar con aire torero. -Bueno, vamoz zeñore- dijo, y don Fausto notó que el ilustre Pipot, por la influencia del instrumento que llevaba en la mano, hablaba ya en andaluz. [...] (Baroja, 1919: 184).

Puede que Zavala acierte en lo de flaco, capa española y perro de lanas, pues es cierto que a Sawa siempre le acompañaban sus perros. También se podría relacionar con que aquello de que es raro o que ofrece un lugar pobre para vivir. Es más, Baroja hace que resida en la calle Galande de París, que se encuentra en el Barrio Latino, barrio en el que residió Sawa durante su estancia parisina, y que le gusten los juegos de mesa. Más allá de estas pequeñas coincidencias, nada se puede sacar en claro. Menos aún tras leer que Pipot era tartamudo (pese a que el hablar a gritos sí se pudiese relacionar con sus exageradas declamaciones). También se dice que hablaba catalán, y aunque Sawa residió en Barcelona, fue por poco tiempo. A pesar del perfecto castellano y el argot de París, mejor hubiera sido sustituir el catalán por el andaluz. Sin embargo, el personaje habla andaluz cuando coge la guitarra. ¿Quiere condensar así Baroja todos los lugares geográficos que en los que residió el bohemio?

En contraposición, extraña bastante que Pipot estudie Medicina (Baroja, 1919: 134), cuando el propio Pío Baroja era médico. Además, Pipot tiene demasiado protagonismo en la vida de Fausto cuando es sabido que Baroja y Sawa se encontraban 
y charlaban pero no iban juntos de taberna en taberna. Con ello, no pretendemos vislumbrar en Fausto a Baroja, sino dar a entender que, si Baroja no convivía con Sawa, le resultaría imposible relatar sus peripecias con precisión. Aunque fuese de oídas, tampoco serían fieles a la realidad; y, en el hipotético caso de que intentasen ser realistas, forman parte de una novela donde la literatura difumina toda correspondencia verosímil. Todo ello sin perder de vista que cualquier semejanza con Sawa debería tener cierta carga de connotaciones negativas de la bohemia, cosa que aquí no sucede de modo flagrante. Por último, el hecho de que retrotraiga el ambiente de la novela a 1866 acaba por distorsionar cualquier intención de crónica que pudiese tener, incluso si aceptásemos los juegos cronológicos barojianos y nos imaginásemos a un Sawa de unos cuarenta y cinco años residiendo aún en París...

En definitiva, son bastante débiles los hilos con lo que se pueden sujetar los argumentos para identificar a Sawa con Pipot. Pero podemos llegar a distinguir cierta esencia o inspiración por parte del vasco en el sevillano, teniendo presente, en todo momento, que "basado en" no puede significar en ningún caso "es".

Más interesante se presenta la relación que se percibe en el personaje César Andion:

La literatura le dio algunos disgustos a don Fausto. Uno fue el conocimiento de un bohemio llamado César Andion. A los quince días de aparecer su primer artículo se presentó en casa de don Fausto un hombre que le hizo pasar una tarjeta que decía así: "César Andion, poeta".

César venía a felicitar a don Fausto, a darle un abrazo fraternal y a pedirle diez francos. Andion era un andaluz que vivía hacía tiempo en París y que había tomado el aire de los bohemios del barrio Latino.

Era ya viejo, con la barba con hilos de plata y los ojos tristes de borracho. Perezoso como un turco, endiabladamente vanidoso, incapaz de trabajar, se pasaba la vida en un continuo ajetreo más duro que cualquier trabajo. Tenía una seriedad de embaucador interrumpida a ratos por una sonrisa de pillo de playa.

César comenzó adulando a don Fausto de una manera escandalosa; recitó luego con una solemnidad sacerdotal versos de Baudelaire, y cuando tomó el dinero, estrechó con todas sus fuerzas la mano de don Fausto y se marchó inmediatamente. Pocos días después don Fausto se encontró al bohemio en la calle. - Me tienes que convidar a una verde -le dijo tuteándole. —Bueno. — ¿Cuánto dinero llevas? - Cinco o seis francos.

-Entonces a dos verdes. A ti no te conviene beber; no podrías escribir esos artículos que escribes, o quizá los escribirías mejores, porque, la verdad, tu prosa es bastante vulgar.

Don Fausto se sintió hondamente mortificado. Entraron en un café; Andion pidió ajenjo y comenzó a echar agua poco a poco en la copa. — La musa verde, ¿eh?... -murmuró- todos los grandes hombres beben ajenjo...

Ahora te recitaré algo del maestro.

— ¿De qué maestro? -preguntó don Fausto. — ¿De qué maestro ha de ser?... Del único, de Baudelaire; ¿tú entiendes el francés?

—No muy bien. —Entonces eres un pobre diablo. — ¡Pse!

- ¿Y por qué no entiendes bien el francés? - Porque hace poco tiempo que estoy aquí.

A usted le sucedería lo mismo. — A mí no... porque soy Dios-. [...] No, no me mire usted con esos ojos espantados, señor don Fausto Bengoa: usted no es nadie 
a mi lado. Porque haya usted escrito unos cuantos artículos despreciables, no crea usted que puede compararse conmigo.

A los pocos días don Fausto vio a Yarza y le preguntó: - ¿Quién es ese César Andion? — ¿Ha ido a pedirle a usted dinero? —Sí. ¿Quién es? —Un bohemio de tantos, de esos que han dejado pasar la hora de la gloria y no han llegado a tiempo más que para la del ajenjo.

— ¿Ha escrito algo? —Sí; creo que sí. — ¿Y tiene talento? —Eso dicen. — ¿Y de qué vive? - Vive del prestigio de lo que pudo hacer.

Algunos amigos suyos dicen: ¡El día que ese se ponga a trabajar! — ¿Pero vale o no? - Yo creo que no. Tiene un repertorio de frases e ingeniosidades y salidas que son patrimonio común de todas las tabernas del barrio Latino. El primer día ese repertorio sorprende un poco, luego cansa (Baroja, 1919: 283 y ss).

César Andion interviene casi al final de la novela y tiene un papel bastante más secundario que Pipot. Ahora bien, encaja muchísimo mejor con las características sawianas. O, dicho de otro modo, encaja con lo que Baroja pensaba de él y con el concepto que tenía de la bohemia. Tengamos en cuenta que Pipot es del agrado de Fausto, siendo que la presentación de Andion comienza con "La literatura le dio algunos disgustos a don Fausto". Se matiza claramente que es un bohemio, andaluz, que vivía en París y tenía los aires del Barrio Latino (aunque vuelva a situarlo ya canoso en la ciudad francesa), además de que daba grandes apretones de manos. Lo tilda de vago, idea que muchos tenían de Sawa, embaucador, escandaloso (una vez más en conexión con sus ademanes exagerados) y afirma que recitaba soberbiamente a Baudelaire (posiblemente, como ya apuntaba Phillips, es un cambio por Verlaine). Asimismo, es arrogante, opinión que no solo tiene Baroja, pues muchos son los que hablan de su soberbia y del convencimiento de su superioridad. Acepta que tiene talento pero que es más lo que escribió que lo que escribe, y esto también enlaza con las confesiones que hacía Baroja en Juventud, egolatría sobre el reconocimiento de elocuencia de Sawa pero incompatibilidad entre sus estilos. Sin perder de vista que la producción novelística de Sawa se concentra en sus años de juventud, quedando para la posteridad su faceta como cronista. Tampoco es desconocida la afición de todo el gremio de bohemios a la bebida. En concreto, el ajenjo del que habla Baroja no es más que la absenta, un licor verde de muy alta graduación ${ }^{10}$, del que decían con ánimo jocoso que "hacía aparecer a las musas". Pero, sin duda, el episodio que más se acerca a la realidad es en el que Andion pide a Fausto dinero para que pagase las consumiciones. Ya se ha visto cómo Baroja narra el momento en el que conoció a Sawa, cómo le pidió tres pesetas y las fue a buscar a su casa para pagar lo que Sawa y Cornuty habían bebido en la taberna. El problema viene a la hora de trasladar las anécdotas a la realidad pues nos volvemos a encontrar con esa condensación del tiempo de la que hablábamos. Las tres pesetas no son los "cinco o seis francos" porque las pesetas se prestaron en la plaza de Herradores de Madrid, no en el Barrio Latino de París. Y porque si Andion es Sawa, Fausto tiene que ser Baroja, que es quien realmente prestó el dinero. Y no es así porque don Fausto tiene una hija cuando Baroja permaneció toda su vida soltero y no tuvo descendencia. Aunque en la ficción todo vale... 


\section{Conclusiones}

Tras este riguroso estudio de los personajes barojianos de los que en algún momento la crítica ha señalado que se trataba de Alejandro Sawa, ha quedado de manifiesto que algunas identificaciones se habían llevado demasiado lejos y a otras no se les había prestado la atención suficiente.

No podremos nunca saber a ciencia cierta qué personaje bohemio de Baroja causó la ira de Alejandro Sawa, pero podemos aproximarnos tras la comparación con la realidad: Juan Pérez del Corral encarna de un modo exagerado la personalidad de Sawa y su desenlace entre llamadas de socorro fue casi premonitorio, y el simple hecho de hacerle morir de tuberculosis sería motivo suficiente para que el bohemio sevillano se molestase. En cuanto a Betta, poco habría que decir, pues se trata de una aparición fugaz y se le describe como un tipo callado. Aunque pudiese encajar en la descripción física, no sería difícil encontrar a escritores e intelectuales que también lo hiciesen. Es cierto que es el que mejor responde a la prosopografía, pero esto nos da a entender que Baroja siempre toma un mismo tipo de modelo cuando quiere reflejar ese tipo de vida y la estética que lleva aparejada. No hay duda de que Alejandro era el líder y el más significativo de aquella pandilla, por eso no es de extrañar que el escritor vasco, pese a no querer calcar estrictamente a Sawa en sus novelas, tome de él ciertos rasgos definitorios que le ayudan a configurar los prototipos.

Respecto a García Pipot y César Andion, la balanza se inclina a favor del último. A Pipot le sucede algo parecido a Betta: encaja en la descripción, sobre todo en lo relativo a las penurias económicas y la debilidad por los perros, pero falla en detalles de suma importancia como la tartamudez, sus estudios de Medicina o la buena relación con el protagonista de la novela. En cambio, Andion se acerca más a la realidad; es el más identificable con Sawa de todos los personajes bohemios barojianos y, dado que Los últimos románticos datan de 1906, tiene tantas probabilidades como Juan Pérez del Corral de ser conocido por Sawa y constituir el motivo de su enfado.

En cuanto a Aurora roja, ha quedado más que argumentado quiénes pretenden ser el francés y el ruso. Evidentemente, como ha ocurrido con todos los personajes, también están literaturizados, sin embargo, tienen apoyos bastante literales en la realidad que los hace perfectamente reconocibles. Esto no rompe del todo el vínculo con Alejandro Sawa pues, aunque esta vez no fue el elegido para encarnar a los desarrapados, lo fueron dos amigos suyos muy cercanos, con quienes compartía un estilo de vida y a Baroja le sirven igualmente para transmitir la misma esencia. Es más, viene al caso dejar apuntado que Valle-Inclán también tomó como modelos a Ernesto Bark y a Enrique Cornuty para crear otros dos personajes. Estos son la señorita Cornuty de La cara de Dios (1900), quien igual que Cornuty es bizca, aunque el gallego opta por feminizarlo; y Basilio Soulinake de Luces de Bohemia, a quien se describe como: "un hombre alto, abotonado, escueto, grandes barbas rojas de judío anarquista y ojos envidiosos, bajo el testuz de bisonte obstinado. Es un fripón periodista alemán, fichado en los registros policíacos como anarquista ruso y conocido por el falso nombre de Basilio Soulinake" (Valle-Inclán, 1987: 183-184). Bark también se reconoció en el personaje y no solo se ofendió, sino que llegó a agredir al propio Valle-Inclán.

En definitiva, Alejandro Sawa y su círculo más íntimo gozaban, para bien o para mal, de suficiente fama y eran lo bastante significativos como para transmutarse en personajes de novelas. Y decimos personajes, en plural. 
Consideramos que ha sido acertado poner el foco sobre caracteres que han sido poco estudiados, no solo porque la comparación de Sawa con Villasús se haya reiterado dejando al margen estas otras comparaciones, sino porque se crearon cuando Sawa aún vivía y porque, a diferencia de Villasús, de quien se recrea el velatorio, los otros bohemios barojianos aparecen vivos la mayor parte del tiempo, definiéndose mucho mejor su personalidad.

Acabaremos insistiendo en que Baroja nos ha demostrado que Alejandro Sawa y sus amigos ${ }^{11}$ subyacen bajo ciertos personajes, pero no busca hacer una copia exacta. En unas novelas donde llegan a desfilar hasta ochenta personajes, son varias las veces que sus protagonistas, que tampoco son un reflejo fiel de Baroja, se topan con gentes de un mundo que no son del agrado del vasco. Baroja se basa para su creación en algunos rasgos de lo que conoce y lo toma como referente, aunque sea por antítesis y por mucho que intente ampliar el elenco variando ciertas características.

\section{Obras citadas}

\section{Fuentes primarias}

Bark, Ernesto, La Santa Bohemia, Madrid, Biblioteca Germinal, 1913. [En línea: http://bdhrd.bne.es/viewer.vm?id=0000085624\&page $=1$ (Consulta: 27.03.2017)]

Baroja, Pío, Aurora roja, Madrid, Librería de Fernando de Fé, 1904.

- Juventud, egolatría, Madrid, Rafael Caro Raggio Editor, 1917.

— Los últimos románticos, Madrid, Rafael Caro Raggio Editor, 1919.

- Galería de tipos de la época. Desde la última vuelta del camino, vol. IV, Madrid, Biblioteca Nueva, 1947.

- Reportajes. Desde la última vuelta del camino, vol. VII, Madrid, Biblioteca Nueva, 1949.

- Silvestre Paradox, y Paradox, rey, ed. L. Mateo Díez, Madrid, Consejería de Educación y Cultura, 1998.

-Desde la última vuelta del camino, Obras completas, vol. II, Barcelona, Tusquets, 2006.

Baroja, Ricardo, Gente de la generación del 98, Barcelona, Juventud, 1969.

Sawa, Alejandro, Iluminaciones en la sombra, ed. Iris M. Zavala, Madrid, Alhambra, 1977.

Valle-Inclán, Ramón (del), Luces de Bohemia, ed. A. Zamora Vicente, Madrid, Espasa-Calpe, 1987.

\section{Fuentes secundarias}

Álvarez, Dictino, Cartas de Rubén Dario, Madrid, Taurus, 1963.

Correa Ramón, Amelina, Alejandro Sawa, luces de bohemia, Sevilla, Fundación José Manuel Lara, 2008.

Gutiérrez Carbajo, Francisco (ed.), Alejandro Sawa, Criadero de curas, Madrid, Biblioteca de Autores Españoles, 1999.

11 El círculo más íntimo de Alejandro Sawa estaba configurado por: “Sus amigos: Valle-Inclán, Zamacois, Darío, Bark, Nakens, Enrique Cornuty, Salvador Rueda, Gómez Carrillo” (Zavala, 1977: 35). 
Phillips, Allen, “Algo más sobre la bohemia madrileña: testigos y testimonios”, Anales de Literatura Española, 4 (1985), pp. 327-363. [En línea: http://rua.ua.es/dspace/bitstream/10045/7562/1/ ALE_04_15.pdf. DOI: 10.14198/ALEUA.1985.4.15 (Consulta: 28.03.2017)]

Thion Soriano-Mollá, María Dolores, Ernesto Bark: un propagandista de la Modernidad (1858-1924), Valencia, Instituto de Cultura Juan Gil-Albert, 1998. [En línea: http://www.cervantesvirtual.com/obra/ernesto-bark--un-propagandista-de-la-modernidad-1858-1924/ (Consulta: 28.03.2017)]

Zamora Vicente, Alonso, Valle-Inclán. Novelista por entregas, Madrid, Taurus, 1973.

Zavala, Iris M. (ed.), Alejandro Sawa, Iluminaciones en la sombra, Madrid, Alhambra, 1977. 